How to Become a Good Mechanic. Intended as a practical guide to selftanght men, etc., etc. By John Phin. Second edition, rewritten and greatly enlarged. I 2 mo., pp. 68, paper. New York: Industrial Publishing Company, 1901. (Price, 25 cents.)

The purpose of this work, as explained by the author, is to give to students who are encleavoring to pursue a course of study without a teacher a series of suggestions and hints as to "what to study, how to begin, what difficulties will be met and how to overcome them - in a word, how to carry on such a course of self-instruction as will enable the young nnechanic to rise from the bench to something higher."

W.

\title{
Franklin Institute.
}

[Proceedings of the stated meeting held Wednesday, September 18, 19or.]

HALI, OF 'THE FRANKI,IN INSTITUTE, Phimadir.pha, September i 8 , rgor.

Vice-President Triso. D. RAND in the chair.

Present, 84 members and visitors.

Additions to membership since last month, 9 .

The gift was reported of a marble bus: (with pedestal) of the late John Struthers, one time an active member of the Franklin Institute. The gift was accepted with the thanks of the Institute, and the Secretary was directed to make suitable acknowledgnent to the giver, Mrs. Helen Struthers Dunn, of Philadelphia.

Mr. Wm. McDevitt, Inspector of the Philadelphia Board of Fire Underwriters, gave a series of illustrations designed to exhibit the causes of explosions at fires, especia1ly where chemical substances, such as chlorates, nitrates, volatile oils, collodion, guncotton, etc, are involved. The speaker drew largely upon his extensive experience with such explosions, and urged the importance of instructing workmen who handle dangeronsty inflammable -or explosive substances in factories, etc, concerning their properties. The experiments made by Mr. McDevitt were striking and instructive. Discussed by Messrs. Fullerton, Goldschmidt and the author.

'Then followed a series of informal communications on the Pan-American Exposition, which were profusely illustrated with the aid of lantern slides. The participants were Mr. Louis E. I,evy, Dr. A. E. Kennelly, Prof. II. W. Spangler and Mr. Carl Hering.

Mr. Joseph Stcinnetz exhibited a number of aluminium plates badly corroded by the action of sea waters. These had formed the hull plates of the American cup yacht Defender.

The exhibit demonstrated in the most effective way the unfitness of this metal for purposes where it is exposed to contact with salt water or to an atmosphere laden with such moisture.

Adjourned.

WM. H. WAHI,

Secretary. 